TAPROBANICA, ISSN 1800-427X. October, 2012. Vol. 04, No. 02: pp. 77-82.

(C) Taprobanica Private Limited, 146, Kendalanda, Homagama, Sri Lanka.

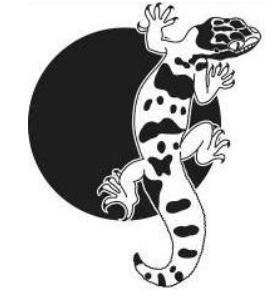

\title{
BREEDING ECOLOGY OF THE CRESTED SERPENT EAGLE Spilornis cheela (LATHAM, 1790) (AVES: ACCIPITRIFORMES: ACCIPITRIDAE) IN KOLLI HILLS, TAMIL NADU, INDIA
}

Varadarajan Gokula

Post Graduate \& Research Department of Zoology, National College, Tiruchirappalli 620001, Tamil Nadu, India; E-mail: gokulae@yahoo.com

\begin{abstract}
The breeding ecology of the crested serpent eagle (Spilornis cheela), focusing on nest-site selection, food habits, and perch-site preference, was studied in the Kolli Hills of Tamil Nadu, India, from May 2005 to May 2010. Thirty-two active nests were located, with nest-site details collected from 27 nests that were accessible. The crested serpent eagle did not construct new nests, but did renew or alter old nests, mainly in December. Both sexes were involved in the nest renewal activities. The clutch size was one, the mean incubation period was 41.5 days, and the mean fledging period was 64.5 days. Nests were found largely along riverine patches. The results indicate the mature and less disturbed riverine forests with large sized trees are critical for the breeding and conservation of this species. The food habits of the eagle were known from prey items brought into the nest by the adult to feed the chick and prey items fed on by the adult. In total, 173 feeding observations were made and the prey items belonged to 17 species of vertebrates. The crested serpent eagle largely preferred reptiles, which accounted for $74 \%$ of their diet, followed by birds, which accounted for $18 \%$ of their diet. A total of 1237 perching records were observed. The crested serpent eagle preferred to perch on the outer canopy of the trees found largely in the forest edges.
\end{abstract}

Key words: Clutch size, prey preference, perching preference, nesting behaviour, raptors, avian ecology, Indian biodiversity

\section{Introduction}

Raptors are one of the most threatened groups of birds (Brown \& Amadon, 1968) and thus knowledge of their ecological requirements is very crucial for conservation activities. The crested serpent eagle (CSE hereafter), Spilornis cheela, is classified as a raptor of least concern

(Birdlife International, 2010). It is a medium sized raptor whose range includes most of the Indo-oriental region (Brown \& Amadon, 1968). Over 20 sub-species are recognized around the world, all of which are associated with tropical and subtropical forests (Brown \& Amadon, 
1968). Within the Indian sub-continent, there are five subspecies of the CSE (two endemic to Andaman and Nicobar Islands) while the sixth subspecies is endemic to Sri Lanka (Naoroji, 2006). Although the CSE is found in a widearray of suitable habitats and bio-geographical zones of India, the ecological requirements of the CSE, like most other raptor species, is poorly documented in India. However, a few behavioural descriptions are available elsewhere (Naoroji 1994, 1999; Naoroji \& Monga, $\quad 1983 ; \quad$ Baker 1914; Dharmakumarsinhji, 1939; Purandare, 2002; Waghray et al., 2003). Hence, an attempt was made to study the breeding ecology, focusing on nest-site selection, food habits and perchsite preference, of CSE in Kolli Hills, Tamil Nadu, India, from May 2005 to May 2010.

\section{Materials and Methods}

Study area: Kolli Hills $\left(11^{\circ} 11^{\prime}-11^{\circ} 30^{\prime} \mathrm{N}\right.$, $78^{\circ} 16^{\prime}-78^{\circ} 29^{\prime}$ E) covers an area of about 485 $\mathrm{km}^{2}$ (Fig. 1). Average rainfall ranges from 787 - $910 \mathrm{~mm}$ in the plains, while it varies from $1189-1333 \mathrm{~mm}$ in the hills. On the plateau, temperature fluctuates from $10-30{ }^{\circ} \mathrm{C}$, but in the foothills and adjoining plains it varies from $20-40{ }^{\circ} \mathrm{C}$. The total human population of Kolli Hills is about 37, 516, with a homogeneous community of $97 \%$ Malayalis that have largely been managing the landscape. Most Malayalis are directly involved in agricultural activities.
Among the crops cultivated, Cassava dominates some parts, while millet dominates other areas. The encroachment into forests by local farmers, bauxite mining activity, land-use pattern changes, disturbance of water regime, and clogging of stream channels are the primary threats to the biodiversity of Kolli Hills. However, the hunting and gathering activities of the local inhabitants may not be overlooked in this issue.

The following forest types have been observed in Kolli Hills; Shola forest occurs between the altitude 900 and $1370 \mathrm{~m}$ a.s.l. and receives ample rainfall during the north-east monsoon. Memecylon edule, Persea marmacranth, and Memecylon umbellatum are the dominant tree species. The tropical dry evergreen forest occurs between $900 \mathrm{~m}$ and $1200 \mathrm{~m}$ a.s.l., with Ammora canarana, Canarium strictum, Syzyium cumin, and Filicium decipiens the dominant tree species. Semi-evergreen forest occurs between $400 \mathrm{~m}$ and $1200 \mathrm{~m}$ a.s.1., with Persea macrantha, Epiprinus mallotiformis and Terminalia bellarica dominating this forest type. Thorn forest occurs between $220 \mathrm{~m}$ (foothills) and $1100 \mathrm{~m}$ a.s.l. The dominant species is Moringa concanensis. Besides natural forests, plantations of eucalyptus, bamboo, tamarind, and silver oak are also present.

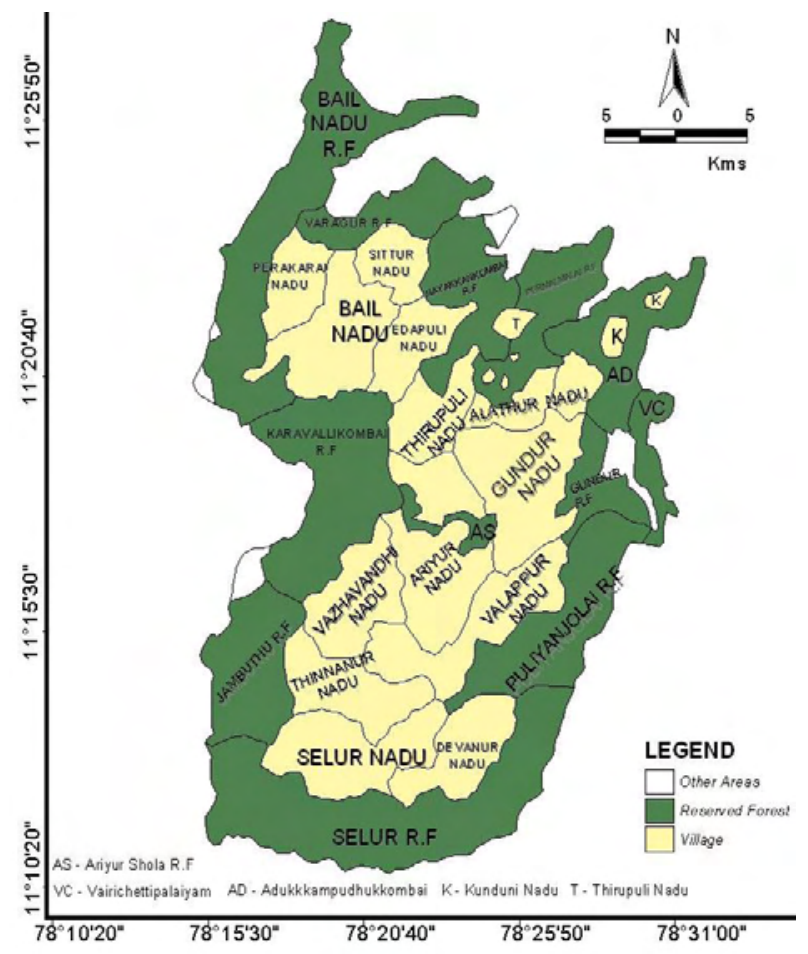

Figure 1: The map of administrative units of Kolli Hills, Tamil Nadu, India. 
Data collection: Nest searches were made by examining trees and substrates suitable for nesting. An active nest was identified if adults were seen performing breeding activities (e.g., nest-building or renovation, incubation, feeding the young) in or adjacent to the nest. Dates of the presence of eggs in the nests were recorded to estimate the breeding seasonality of CSE. I collected data on the nests [height (m), length $(\mathrm{cm})$, and width $(\mathrm{cm})]$, trees that nests were found in [tree-height $(\mathrm{m})$, and diameter at breast height $(\mathrm{cm})]$, and the surrounding landscape of the nest trees [ground-cover (\%), shrub-cover (\%), distance to water (rank), distance to settlement (km), and canopycloseness (\%)]. The landscape variables were measured within a 0.07 ha circular plot centred at the nest-tree as suggested by Titus \& Mosher (1981). Percentage of vegetation cover (shrub and ground) was visually estimated. The percent canopy-cover immediately over the nest was measured using a hand mirror marked with a grid. The shaded area was estimated as canopy cover (Martin \& Roper, 1988). All parameters except nest measurements were compared with similar measurements at randomly selected sites to identify the factors responsible for selecting a nest-site. Random sites were selected on the basis of a place having potential as a nest-site and being close enough to the located nest sites. The study area was divided into $50 \mathrm{~m} \times 50 \mathrm{~m}$ grids and numbered on an enlarged topographic map. Twenty seven grids were selected using lot method and were identified in the study area. Once the approximate grid or site was located, the nearest tree or shrub was made the centre of the random plot.

Direct visual observation was used to examine food habits of the CSE. I opportunistically recorded the prey items delivered to the chick by adult CSEs and the prey items eaten by CSE. Observations were made using Vanguard DCF10 X 42 binocular and Audubon Spotting Scope $(15-60 \mathrm{X}$ zoom) from a distance with minimal disturbance from the observer. Prey items were identified up to species level if possible. Left over/fallen prey remains, if any, were collected from the ground to confirm the identity if needed. In total, 173 food habitobservations were made for the present study.

In order to understand the perching site preference, details viz. perching height, status of the perching tree (live or dead), and perching canopy (inner canopy [close to trunk], outer canopy [away from trunk], or edge of the canopy) were recorded for all CSE sighted. A total of 1237 perches were observed.

Data analysis: Mann-Whitney $U$ were performed on ranked variables (Ground-cover, shrub-cover, distance to water, distance to settlement, canopy-closeness) and Univariate analyses of variances (ANOVA) were performed on other measured variables (Nesttree-height, and Girth at breast height) to compare nest-sites and random sites (Sokal \& Rohlf, 1981). Results are reported significant if associated with a value of $\mathrm{P}<0.05$.

\section{Results and Discussion}

CSE started breeding mainly in late November and completed by early April (this includes courtship to fledging of the young). However, the season is extremely variable within India, as CSE breeds much later (between February and July) in the Northern India (Naoroji, 2006). Circular soaring and calling, a frequent mode of display during the breeding season, were performed during late November. Talon locking was observed in one pair. Mating of CSE was observed on trees on five occasions by different pairs. Both sexes find the available old nest and start renovating. In total, 32 nests were located; however, data were collected on only 27 accessible nests. No nest was constructed afresh, but old nests were found renovated for use $(n=27)$. All the nests were renovated mostly in December with fresh twigs and branches. Fresh green leaves were found inside the nests in some cases $(n=16)$ during the initial period of incubation and in all cases during the later stage of incubation. Replacement of old leaves with new ones during the fledgling period was also observed. The reasons for the use of green material inside the nest concur with Nores \& Nores (1994); it may be a strategy to diminish infestation by ectoparasites. Both sexes were involved in nest renovation activity. Traditional use of nest-site every year is a strategy adopted probably to avoid spending energy for constructing nests as reported by Collias \& Collias (1984). Clutch size was invariably single for all cases and the mean incubation period was 41.5 days $(n=27$, range 37 to 42 days). Only females were involved with incubation. The male often guarded the nest when the female left to forage. 
The mean fledging period was 64.5 days (range 59-65 days, $\mathrm{n}=27$ ). However, an average incubation period of 38.5 days (range 37 to 42 days, $\mathrm{n}=16$ ) and fledging period of 62 days (range 59-65 days, $\mathrm{n}=16$ ) in the same locality was reported in a previous study (Gokula, 2009). Nests were found largely along the riverine patches of Terminalia bellirica (6), Dalbergia latifolia (8), Tectona grandis (3),
Lagerstroemia lanceolata (7), Mangifera Indica (6), and Bombax ceiba (2). Nests were mostly located in the upper one-third of a tree where two or more lateral branches extended from the trunk to form a platform. The nests were placed at a mean height of $18.5 \mathrm{~m}$ (range 15.2 to $24.5 \mathrm{~m}, \mathrm{n}=27$ ) from the ground level. The mean length and width of the nests were $103.5 \mathrm{~cm}$ and $57.3 \mathrm{~cm}$ respectively (Table 1 ).

Table 1: Nest-site characteristics of the CSE in comparison with random-site characters; ns, not statistically significant

\begin{tabular}{|c|c|c|c|c|c|}
\hline \multirow{2}{*}{ Variables } & \multicolumn{2}{|c|}{ Nest-plot $(\mathrm{n}=27)$} & \multicolumn{2}{|c|}{ Random plot $(n=27)$} & \multirow{2}{*}{$P$ value } \\
\hline & Mean & $\mathrm{SD}+$ & Mean & $\mathrm{SD}+$ & \\
\hline Nest-height (m) & 18.5 & 2.8 & - & - & - \\
\hline Nest-length $(\mathrm{cm})$ & 103.5 & 42.5 & - & - & - \\
\hline Nest-width (cm) & 56.8 & 11.8 & - & - & - \\
\hline Nest-tree-height (m) & 24.1 & 2.4 & 15.6 & 3.3 & $<0.01$ \\
\hline GBH (cm) & 292.7 & 55.5 & 202.7 & 92.2 & $<0.05$ \\
\hline Ground-cover (\%) & 27.6 & 14.8 & 42.6 & 30.0 & ns \\
\hline Shrub-cover $(\%)$ & 45.4 & 16.2 & 40.7 & 17.9 & $\mathrm{~ns}$ \\
\hline Distance to water (rank) & 1.0 & 0.0 & 1.9 & 0.4 & $<0.01$ \\
\hline Distance to settlement $(\mathrm{km})$ & 3.4 & 1.5 & 1.2 & 0.8 & $<0.01$ \\
\hline Canopy-closeness (\%) & 77.6 & 4.0 & 45.1 & 14.5 & $<0.01$ \\
\hline
\end{tabular}

Table 2: List of prey items of CSE recorded in Kolli Hills

\begin{tabular}{|c|c|c|c|c|}
\hline Prey species & & Occurrence & $\%$ of oc & arrence \\
\hline Fishes & & & Individua & Group \\
\hline & Unidentified & 1 & 0.6 & 0.6 \\
\hline Amphibians & & & & \\
\hline & Unidentified & 12 & 6.9 & 6.9 \\
\hline Reptiles & & & & \\
\hline & Calotes rouxi & 5 & 2.9 & 74.0 \\
\hline & Draco dussumieri & 1 & 0.6 & \\
\hline & Psammophilus dorsalis & 3 & 1.7 & \\
\hline & Chamaeleon zeylanicus & 2 & 1.2 & \\
\hline & Ptyas mucosus & 22 & 12.7 & \\
\hline & Oligodon arnensis & 7 & 4.0 & \\
\hline & Dendrelaphis tristis & 22 & 12.7 & \\
\hline & Xenochrophis piscator & 1 & 0.6 & \\
\hline & Ahaetulla nasuta & 29 & 16.8 & \\
\hline & Naja naja & 2 & 1.2 & \\
\hline & Daboia russellii & 18 & 10.4 & \\
\hline & Unidentified snake & 16 & 9.2 & \\
\hline Birds & & & & \\
\hline & Columba livia & 4 & 2.3 & 17.9 \\
\hline & Acridotheres tristis & 3 & 1.7 & \\
\hline & Terpsiphone paradise & 4 & 2.3 & \\
\hline & Aegithina tiphia & 5 & 2.9 & \\
\hline & Artamus fuscus & 14 & 8.1 & \\
\hline & Oriolus oriolus & 1 & 0.6 & \\
\hline Mammals & & & & \\
\hline & Funambulus palmarum & 1 & 0.6 & 0.6 \\
\hline
\end{tabular}


Analysis of variance and other univariate procedures indicated that CSE did not select nest-sites randomly in Kolli Hills. Apparently the sites were selected to fulfill specific nesting requirements. CSE selected sites with microhabitat features such as availability of larger and broader trees, closed-canopy, proximity to water source, and farther from human settlement. Of the environmental variables, except ground cover and shrub cover, all others (nest-tree height $\mathrm{F}=18.55, \mathrm{P}=0.0004$; nest-tree girth at breast height $\mathrm{F}=6.0375$, $\mathrm{P}=0.0244$; distance to water $\mathrm{U}=12.0$, $\mathrm{P}=0.0006$; distance to settlement $\mathrm{U}=12.0$, $\mathrm{P}=0.0048 ;$ and canopy-closeness $\mathrm{U}=0.5$, $\mathrm{P}=0.0001$ ) differed significantly between nestsites and random-sites (Table 1).

Table 3: Perching site preference of CSE

\begin{tabular}{lccc}
\hline & & $\begin{array}{c}\text { No of } \\
\text { perches }\end{array}$ & $\begin{array}{c}\text { perching } \\
\text { occurrence } \\
\text { \% }\end{array}$ \\
\hline & $4-5$ & 99 & 8 \\
& $>7-8$ & 99 & 8 \\
Height & $>9-10$ & 470 & 38 \\
class of & $>11-12$ & 198 & 6 \\
Perching & $>12-13$ & 25 & 16 \\
branch & $>13-14$ & 123 & 2 \\
(in m) & $>14-15$ & 25 & 10 \\
& $>15-16$ & 74 & 2 \\
& $>16-17$ & 25 & 2 \\
& $>17-18$ & 25 & 2 \\
\hline Perching & Live & 1150 & 93 \\
tree status & Snag & 87 & 7 \\
\hline Perching & Inner & 173 & 14 \\
canopy & canopy & & 86 \\
preference & Outer & 1064 & \\
\hline & canopy & & \\
\hline
\end{tabular}

The explanation for selecting the broader (larger girth at breast height) and taller trees concur with earlier studies reporting that the larger Accipiters apparently use larger trees to support their massive nests (Gokula, 1999; Shiraki, 1994; Siders \& Kennedy, 1996). Moreover, nest placement between tree branches and trunks facilitates adults to make frequent trips to nests with food, and young to early take off. Brown and Amadon (1968) stated that a nest was in a location allowing the parents free flight into and out of the nest. The CSE needs wider avenues of approach to the nest and thus the nest was positioned higher in the forest canopy for greater accessibility.
Moreover, the CSE is a perch hunter and selection of open habitat would facilitate its accessibility and vigilance over the nest and also the prey. Selas (1997) reported that for larger species, nest-site selection may be a response both to nest predation risk, microclimate, foraging habitat and food supply.

In total, 173 feeding observations were made and the prey items varied from fish to mammals. In general, CSE seems to prefer reptiles more than any other group as they accounted for $74 \%$ of their diet, followed by birds, (18\%). The CSE used a total of 17 vertebrate prey species. Naoroji (1994, 2006), Dharmakumarsinhji (1939), and Purandare (2002) also reported snakes as part of the diet of CSE. On one occasion, CSE even lifted a dead Russell's viper (Daboia russellii) and ate it.

A total of 1237 perching records of CSE were observed. The CSE preferred to perch on the outer canopy of the tree found largely along forest edges. The frequencies of usage of different height classes of perching sites were not equal $\left(X^{2}=1504\right.$, df $\left.=10, P<0.01\right)$. It prefers perches available largely in the $>8-10 \mathrm{~m}$ height classes (Table 3). The CSE scan for prey from a high lookout, usually from a tree, then plunge down and capture the prey. Hence, selecting moderate height classes may be to get a wider opportunity to execute their hunting strategy. Moderately open habitats and perching at moderate heights may be crucial for the CSE to improve their foraging success.

In summary, CSE constructs no new nest but renews or alters the old available nests preferably on the riverine patches in Kolli Hills. Both sexes are involved in the renewal activities. The clutch size was single. Mean incubation period and fledging period were 41.5 and 64.5 days, respectively. The CSE consumed 17 vertebrate prey species and showed more preference for reptiles than any other group. The CSE preferred to perch on the outer canopy of the tree found largely along forest edges.

\section{Acknowledgements}

I sincerely thank the University Grants Commission, Hyderabad, Academy of Higher Education, National College, Trichy and Tamil 
Nadu Forest Department, Tamil Nadu for the support.

\section{Literature cited}

Baker, E. C. S., 1914. Some notes on tame Serpent Eagle Spilornis cheela, Avicultural Magazine, 5 (5): 154-159.

BirdLife International 2010. Species factsheet: Spilornis cheela. Downloaded from <http://www.birdlife.org> on 3/6/2010

Brown, L. H. and D. Amadon, 1968. Eagles, Hawks and Falcons of the world. McGraw-Hill, New York: 945

Collias, N. E. and E. C. Collias, 1984. Nest Building and bird behaviour. Princeton University Press, Princeton, New Jercey: 336.

Dharmakumarsinhji, K. S., 1939. The Indian Crested Serpent Eagle Spilornis cheela. Journal of Bombay Natural History Society, 41 (1): 177.

Gokula, V., 1999. Bird communities of the thorn and dry deciduous forests in Mudumalai Wildlife sanctuary, Tamil Nadu, India. Ph.D thesis, Bharathiyar University, Coimbatore, Tamil Nadu, India: 186.

Martin, T. E. and J. J. Roper, 1988. Nest Predation and nest-site selection of a western population of the Hermit Thrush. Condor, 90: 5157.

Naoroji, R. K., 1994. Observations on the courtship, nesting and hunting behaviour of the Crested Serpent Eagle Spilornis cheela. Journal of Bombay Natural History Society, 94 (2): 398400.

Naoroji, R. K., 1999. Status of diurnal raptors of Corbett National Park with notes on their Ecology and Conservation. Journal of Bombay Natural History Society, 96 (3):387-398.

Naoroji, R. K., 2006. Birds of prey of the Indian Subcontinent. Om Books International, India: 692.

Naoroji, R. K and S. G. Monga, 1983. Observations on the Crested Serpent Eagle Spilornis cheela in Rajpipla forests - South Gujarat. Journal of Bombay Natural History Society, 80 (2): 273-285.
Nores, A. I. and M. Nores, 1994. Nest building and nesting behaviour of the Brown Cacholote. Wilson Bulletin, 106 (1): 106-120.

Purandare, K., 2002. Attempt by the Crested Serpent Eagle Spilornis cheela to seize the Indian Cobra Naja naja. Journal of Bombay Natural History Society, 99 (2): 299.

Selas, V., 1997. Nest-site selection by four sympatric forest raptors in southern Norway. Journal of raptor Research, 31 (1): 116-125.

Shiraki, S., 1994. Characteristics of white-tailed sea eagle nest sites in Hokkaido, Japan. Condor, 96: 1003-1008.

Siders, M. S. and P. L. Kennedy, 1994. Nesting habitat of accipiter hawks: is body size a consistent predictor of nest habitat characteristics? Studies in Avian Biology, 16: 9296.

Sokal R. R. and F. J. Rohlf, 1981. Biometry, $2^{\text {nd }}$ edition. W. H. Freeman \& Company, New York: 937.

Titus, K. and J. A. Mosher, 1981. Nest site habitat selected by woodland hawks in the central Appalachians. Auk, 98: 270-281.

Waghray, P., I. Siddiqui and A. Siddigui, 2003. Saving Andhra's Tigers. Sanctuary, 23 (6): 5459. 